\title{
Enzymatic Synthesis of Palm Olein-based Fatty Thiohydroxamic Acids
}

\author{
Emad A. Jaffar Al-Mulla*, Wan Md. Zin Wan Yunus, Nor Azowa Bt Ibrahim and \\ Mohd Zaki Ab. Rahman \\ Department of Chemistry, Faculty of Science, University Putra Malaysia, 43400 UPM, Serdang, Selangor, MALAYSIA
}

\begin{abstract}
Fatty thiohydroxamic acids (FTAs) have been successfully synthesized from palm olein and thiohydroxamic acid by a one-step lipase catalyzed reaction. The use of immobilized lipase (Lipozyme RMIM) as the catalyst for the preparation reaction provides an easy isolation of the enzyme from the products and other components in the reaction mixture. The FTAs were characterized using Fourier transform infrared (FTIR) spectroscopy, proton nuclear magnetic resonance $\left({ }^{1}\right.$ H NMR) technique and elemental analysis. The highest conversion percentage $(95 \%)$ was obtained when the process was carried out for 30 hours using urea to palm oil ratio of 6.0: 1.0 at $40{ }^{\circ} \mathrm{C}$. The method employed offers several advantages such as renewable and abundant of the raw material, simple reaction procedure, environmentally friendly process and high yield of the product.
\end{abstract}

Key words: fatty thiohydroxamic acids, enzyme, palm olein, ${ }^{1} \mathrm{H}$ NMR

\section{INTRODUCTION}

Thiohydroxamic acids $[\mathrm{RC}(=\mathrm{S}) \mathrm{NHOH}]$ and thiohydroximates $\left[\mathrm{RC}\left(\mathrm{SR}^{\prime}\right)=\mathrm{NOH}\right]$ contain a moiety with three adjacent nucleophilic atoms $(\mathrm{N}, \mathrm{O}$, and $\mathrm{S})$. These compounds play various roles in analytical and biological chemistry. Thiohydroxamic acids can coordinate with metal, such as $\mathrm{Ni}^{2+}$, and $\mathrm{Cu}^{2+}$ to form colored complexes by use of the sulfur and oxygen atoms. Therefore thiohydroxamic acids and their derivatives are utilized in the detection and quantitative determination of metals in aqueous solutions. The tris-chelates of thiohydroxamic acids and $\mathrm{Fe}^{3+}$ are believed to participate in bacterial iron-transport systems ${ }^{1)}$. The thiohydroximate unit exists in natural occurring mustard oil glucosides, such as glucoapparin, glucotropaeolin, and sinigrin in a separate study. Matsuo and Underhill found that phenylacetothiohydroximate exists in Tropaeolum majus $^{2)}$. They also concluded that phenylacetothiohydroximate is an intermediate in the biosynthesis of benzyl glucosinolate, a mustard oil glucoside ${ }^{3)}$. Thiohydroximates and isocyanates are used as starting materials for the synthesis of the carbamate derivatives. Many carbamates can be used as pesticides ${ }^{4)}$

Some of thiohydroxamic acid derivatives and examination their structures were studied. Monoalkyl derivatives were obtained from alkyl halides and sodium thiohydrox- amate in ethanol ${ }^{2)}$.

In this study, fatty thiohydroxamic acids were synthesized directly from palm oil and urea by a one-step lipase catalyzed reaction. In addition to medicine application of fatty thiohydroxamic acids, the presence of long chains fatty acids from palm olein (mainly 16 and 18 carbon atoms) containing $\mathrm{O}, \mathrm{S}$ and $\mathrm{N}$ atoms suggests fatty amides should be very useful as organic reagents for extraction and separation of metal ions from aqueous solution ${ }^{5-8)}$. Additionally, it is predicted that fatty thiohydroxamic acids will offer the potential application as surfactants for many applications including clay modification to produce polymer nanocomposites $^{9-12)}$

\section{EXPERIMENTAL}

\subsection{Materials}

Palm olein was obtained from NCHOF, Malaysia(The saponification value mg KOH/g oil of palm olein: 198 and the fatty acids composition: C12: 0, C14: 0, C16: 0, C18: 0, C18: 1, C18: 2 and C18: 3) ${ }^{13)}$. Lipozyme RMIM and Novozyme 435 were obtained from Novo Nordisk, Denmark. Thiohydroxamic acid, toluene, chloroform, heptane and hexane were obtained from Merck, Germany.

\footnotetext{
*Correspondence to: Emad A. Jaffar Al-Mulla, Department of Chemistry, Faculty of Science, University Putra Malaysia, 43400 UPM, Serdang, Selangor, MALAYSIA

E-mail: emadaalmulla@yahoo.com

Accepted April 30, 2010 (received for review April 7, 2010)

Journal of Oleo Science ISSN 1345-8957 print / ISSN 1347-3352 online

http://www.jstage.jst.go.jp/browse/jos/
} 


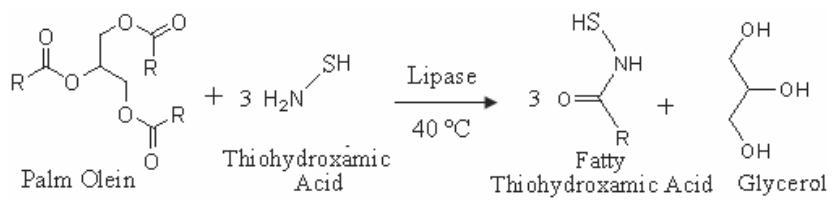

$\mathrm{R}=\mathrm{C} 12: 0, \mathrm{C} 14: 0, \mathrm{C} 16: 0, \mathrm{C} 18: 0, \mathrm{C} 18: 1, \mathrm{C} 18: 2$, or $\mathrm{C} 18: 3$

Scheme 1 Fatty thiohydroxamic acids synthesis from palm olein

\subsection{Synthesis of FTAs}

FTAs were synthesized by reacting $4.12 \mathrm{~g}$ of commercial palm olein in $20 \mathrm{~mL}$ of hexane as a solvent with $4.57 \mathrm{~g}$ of thiohydroxamis acid. The reaction was carried out in the presence of lipase catalyst in a $100 \mathrm{~mL}$ stoppered flask. The mixture was incubated in water shaker batch $(120$ $\mathrm{rpm})$ at $40^{\circ} \mathrm{C}$ for $30 \mathrm{~h}$. Hot hexane was added to the reaction to dissolve the product. The organic phase was then separated from water phase using a separation funnel. To obtain the solid FTAs, the hexane fraction was cooled in a refrigerator at $5^{\circ} \mathrm{C}$ for $3 \mathrm{~h}$, filtered and then reprecipitated by hexane. The product was then dried in an oven at $50^{\circ} \mathrm{C}$. The preparation reaction is shown in the Scheme 1.

\subsection{Measurement of conversion}

The conversion of palm olein into fatty Thiohydroxamic acid carried out by using the optimum reaction conditions as presented in Table 1. The conversion percentage of palm olein reaction was calculated using the following equation (equation 1 ).

$$
\text { Conversion }(\%)=\frac{\text { mmol FATTY THIOHYDROXAMIC ACID }}{\text { mmol fatty acids in palm OLEIN }} \times 100
$$

Depend on nitrogen content of dry fatty thioamides analyzed by the elemental analysis; the amount of mmol product was determined. The amount of mmol fatty acid in the

Table 1 Effect of reaction period on conversion palm olein into FTAs Other reaction conditions: Thiohydroxamic acid/palm olein molar ratio $=6.0: 1.0,20 \mathrm{~mL}$ of hexane, and $40^{\circ} \mathrm{C}$ reaction temperature.

\begin{tabular}{|c|c|}
\hline Reaction time $(\mathrm{h})$ & Conversion(\%) \\
\hline 5 & 12.15 \\
\hline 10 & 29.24 \\
\hline 15 & 45.51 \\
\hline 20 & 66.63 \\
\hline 25 & 82.72 \\
\hline 30 & 95.12 \\
\hline 35 & 95.95 \\
\hline
\end{tabular}

palm olein was calculated from mmol of potassium hydroxide required to saponify $1 \mathrm{~g}$ of palm olein ${ }^{14)}$.

\subsection{Characterization}

Qualitative analysis of amide groups of fatty amides was carried out by observing the colored complex formed after the ethanolic solution of the FTAs reacts with copper ( II ). The functional groups in FTAs were also determined by FTIR spectra. FTIR spectra of the products were recorded by the FTIR spectrophotometer (Perkin Elmer FT-IR-Spectrum BX, USA) using $\mathrm{KBr}$ disc technique

Elemental analyzer (LECO CHNS-932) was used for quantitative analysis of nitrogen contents. The determination was carried out under $\mathrm{N}_{2}$ atmospheric conditions using sulfamethazine as the standard.

The presence of N-H and S-H protons in FTAs was determined by ${ }^{1} \mathrm{H}$ nuclear magnetic resonance (Joel, Japan) using $\mathrm{CDCl}_{3}$ as a solvent.

\section{RESULTS AND DISCUSSION}

\subsection{Enzyme screening}

Two commercial enzymes were screened to select the most efficient enzyme for the reaction. Effect of temperature on conversion palm olein into fatty amides was studied using Lipozyme RMIM and Novozyme 435. In the reaction temperature range from $30^{\circ} \mathrm{C}$ to $60^{\circ} \mathrm{C}$, reaction catalyzed by Lipozyme gave the highest percentage of conversion as shown in Fig. 1 indicating that the immobilized lipase(Lipozyme RMIM) was active for the reaction than

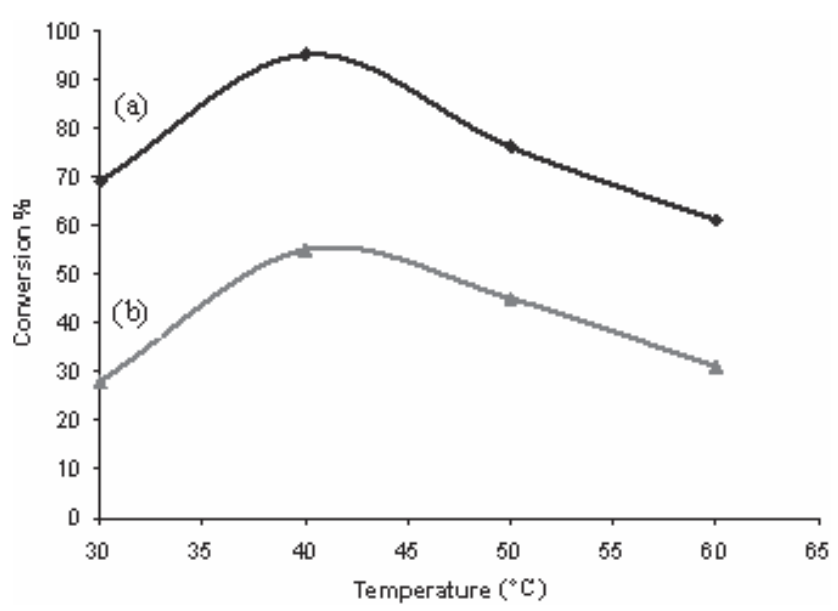

Fig. 1 Effect of temperature on conversion palm olein into FTAs by various enzymes:(a)Lipozyme and(b)Novozyme.

Other reaction conditions: Thiohydroxamic acid/ palm olein molar ratio $=6.0: 1.0,20 \mathrm{~mL}$ of hexane, and $40^{\circ} \mathrm{C}$ reaction temperature. 
Novozyme 435. Therefore, Lipozyme RMIM was used as the lipase in the subsequent experiments. It was also observed that Lipozyme is most efficiently at $40^{\circ} \mathrm{C}$. The percentage of conversion of FTAs decreases above $40^{\circ} \mathrm{C}$ due to destroy its catalytic activity by thermal energy ${ }^{15)}$. Therefore, a reaction temperature of $40^{\circ} \mathrm{C}$ was used for further studies.

\subsection{Effect enzyme amount}

Figure 2 illustrates the results of using different amount of Lipozyme. The percentage of conversion of palm olein increased as the ratio of lipase: palm olein was increased. The highest conversion percentage into FTAs was obtained when the ratio of lipase: palm olein was $35.0 \mathrm{mg}$ to 1.0 mmol. Further increase of lipase to palm olein ratio did not significantly increase the percentage of conversion, as the active sites of the enzyme molecules present may not be fully exposed to the substrate and remain inside the bulk of enzyme particles with out contributing significantly to the reaction ${ }^{16)}$.

\subsection{Effect of organic solvents}

The polarity of different solvents in terms of their log-P values played crucial role. In the course of the amidolysis reaction, various organic solvents were used for the study of the effect of organic solvent on the amidolysis of palm olein. Figure 3 shows that hexane $(\log -\mathrm{P}=3.5)$ was the best solvent for amidolysis of palm olein due to the reaction medium was changed from hydrophilic $(\log -\mathrm{P}<3)$ to hydrophobic $(\log -\mathrm{P}>3)$ organic solvents, the overall efficiency of the enzyme changed ${ }^{17)}$. Therefore, hexane was chosen the solvent in the subsequent experiments.

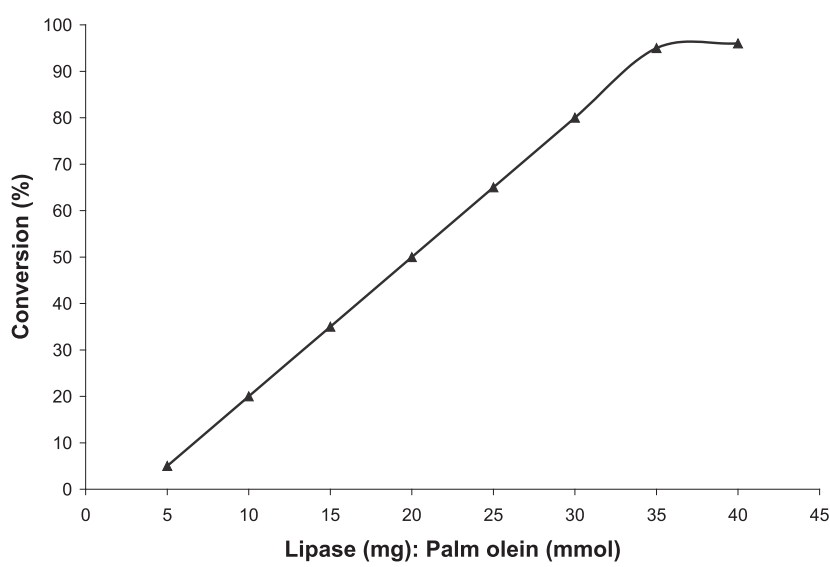

Fig. 2 Effect of catalyst loading on conversion of palm olein into FTAs.

Other reaction conditions: Thiohydroxamic acid/ palm olein molar ratio $=6.0: 1.0,20 \mathrm{~mL}$ of hexane, and $40^{\circ} \mathrm{C}$ reaction temperature.

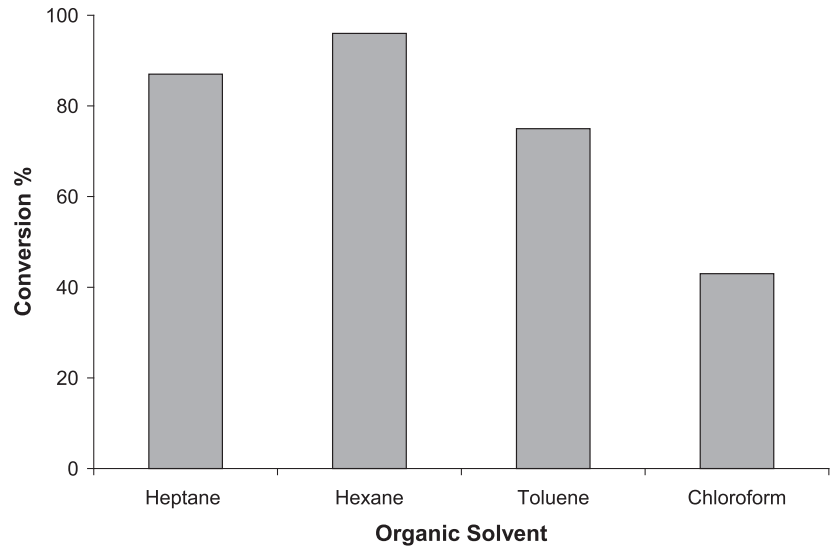

Fig. 3 Effect of catalyst loading on conversion of palm olein into FTAs.

Other reaction conditions: Thiohydroxamic acid/ palm olein molar ratio $=6.0: 1.0,20 \mathrm{~mL}$ of hexane, and $40^{\circ} \mathrm{C}$ reaction temperature.

\subsection{Effect of reaction time}

The time course of enzymatic amidolysis was shown in Table 1. The percentage of conversion into FTAs increased with increasing reaction time. The highest conversion percentage was obtained when the process was carried for 30 $\mathrm{h}$. The reaction rate change after $30 \mathrm{~h}$ was small as the reaction reached the equilibrium state. This result is in agreement with Hacking et $a l^{18)}$.

\subsection{Effect of molar ratio of thiohydroxamic acid to palm olein}

The conversion percentage of palm olein into fatty amides was highest when the ration of thiohydroxamic acid to palm olein was 6.0 mmol: $1.0 \mathrm{mmol}$ as illustrated in Table 2.

Table 2 Effect of molar ratio of thiohydroxamic acid to palm olein on conversion palm olein into FTAs. Other reaction conditions: Thiohydroxamic acid/ palm olein molar ratio $=6.0: 1.0,20 \mathrm{~mL}$ of hexane, and $40^{\circ} \mathrm{C}$ reaction temperature.

\begin{tabular}{|c|c|}
\hline $\begin{array}{c}\text { Thiohydroxamic } \\
\text { acid(mmol): } \\
\text { Palm olein(mmol) }\end{array}$ & Conversion(\%) \\
\hline 1 & 15.72 \\
\hline 2 & 26.22 \\
\hline 3 & 45.76 \\
\hline 4 & 78.86 \\
\hline 5 & 89.09 \\
\hline 6 & 95.20 \\
\hline 7 & 90.12 \\
\hline
\end{tabular}


Table 3 Optimum reaction conditions of conversion palm olein into FTAs.

\begin{tabular}{|l|l|}
\hline \multicolumn{1}{|c|}{ Parameter } & \multicolumn{1}{c|}{ Condition } \\
\hline Lipase & Lipozyme \\
\hline Solvent & Hexane \\
\hline Reaction time & $30 \mathrm{hs}$ \\
\hline Temperature & $40{ }^{\circ} \mathrm{C}$ \\
\hline Ratio Lipozyme(mg): Palm olein(mmol) & $35.0: 1.0$ \\
\hline Ratio thiohydroxamic acid(mmol): Palm olein(mmol) & $6.0: 1.0$ \\
\hline
\end{tabular}

This molar ratio was lower compared to the results of Mohamad et $a l{ }^{13)}$. They stated that the percentage of biosynthesis of fatty hydrazide was highest when the molar ratio of the hydrazine hydrate to palm oil was 13.4: 1. A similar phenomenon was observed by Gunawan et al. ${ }^{16)}$ that shows high concentration of oleyl alcohol inhibited the reaction.

Under the reaction conditions stated above summarized in Table 3, the highest conversion percentage of palm olein into FTAs was around of $95 \%$. The acid value of the final product was $0.39 \mathrm{mg} \mathrm{KOH} / \mathrm{g}$ sample.

\subsection{Characterizations of FTAs}

3.6.1 FTIR spectra

Characteristic bands of palm olein were observed at 2911, 2854, $1749 \mathrm{~cm}^{-1}$ resulting from $\mathrm{C}-\mathrm{H}$ asymmetric stretching of $\mathrm{CH}_{2}, \mathrm{C}-\mathrm{H}$ symmetric stretching of $\mathrm{CH}_{2}$ and $\mathrm{C}$ $=\mathrm{O}$ stretching of ester (glyceride), respectively ${ }^{16)}$. The FTAs spectra show absorption bands at 3314, 2553, 1625 and $1046 \mathrm{~cm}^{-1}$ attributed to -NH group stretching, -SH streching, $\mathrm{C}=\mathrm{O}$ stretching and $\mathrm{C}-\mathrm{N}$ stretching of thiohydraxamic acid, respectively. The disappearance of the peak at $1749 \mathrm{~cm}^{-1}$ and presence of the peaks at 3314, 2553, 1625 and $1046 \mathrm{~cm}^{-1}$ indicate that fatty thiohydroxamic acids have been formed ${ }^{15)}$.

\subsubsection{Complex formation test}

Complexes of thiohydroxamic acid with copper ( II ) is green which is a common color of the complex observed when this metal ion is reacted with amide group ${ }^{3)}$.

3.6.3 ${ }^{1} \mathrm{H}$ NMR spectra of FTAs

$(400 \mathrm{MHz})\left(\mathrm{CDCl}_{3}\right): \delta 0.88\left(\mathrm{t}, \mathrm{J}=9.3 \mathrm{~Hz}, 3 \mathrm{H}, \mathrm{CH}_{3}\right), 1.19$ $\left(\mathrm{m}, \mathrm{H}, \mathrm{CH}_{2}\right), 1.71\left(2 \mathrm{H}, \mathrm{CH}_{2} \mathrm{CH}_{2} \mathrm{CO} \mathrm{NH}\right), 2.01\left(4 \mathrm{H}, 2 \times \mathrm{CH}_{2}\right.$ $\mathrm{CH}=\mathrm{CH}), 2.51\left(\mathrm{t}, \mathrm{J}=10.2 \mathrm{~Hz}, 2 \mathrm{H}, \mathrm{CH}_{2} \mathrm{CO} \mathrm{NH}\right), 4.32(\mathrm{br}, \mathrm{H}$, $\mathrm{SH}), 5.52(2 \mathrm{H}, \mathrm{CH}=\mathrm{CH}), 6.32(\mathrm{br}, \mathrm{s}, \mathrm{H}, \mathrm{CO} \mathrm{NH})$.

\section{CONCLUSION}

This paper describes a novel synthesis of fatty thiohydroxamic acids from palm olein and thiohydroxamic acid by immobilized lipase in presence of hexane as an organic solvent. The method employed offers technical simplicity, high percentage of conversion, easy isolation of enzyme from the products and other components in the reaction mixture. The optimum reaction conditions were as follows: temperature $40^{\circ} \mathrm{C}$, molar ratio of urea to palm olein 6.0 : 1.0, amount of Lpozyme ( $\mathrm{mg}$ ) to amount of palm olein (mmol) 35.0: 1.0 and reaction time 30 hours. Results of qualitative analyses of complex formation, FTIR spectroscopy and ${ }^{1} \mathrm{H}$ NMR technique confirm the formation of fatty thiohydroxamic acids.

\section{References}

1. Richard, A. R. Industrial uses of palm, palm kernel and coconut oils: Nitrogen derivatives. J. Am. Oil Chem. Soc. 62, 255-265 (1985).

2. Litjens, M. J.; Sha, M.; Straathof, A. J.; Jongejan, J. A.; Heijnen, J. J. Competitive lipase catalyzed ester hydrolysis and ammoniolysis in organic solvents: Equilibrium model of solid liquid vapor system. Biotechnol. Bioeng. 65, 347-356 (1999).

3. Nagata, N.; Mizukami, S. Studies on thiohydroxamic acids and their metal chelates synthesis of some thiohydroxamic acids derivatives and their structure. Pharm. Soc. Jpn. 14, 1263-1272(1966).

4. David, M. W.; Toby, J.'Stephen, C. M.; Anne, R. The application of a thiohydroxamic acid (THA) linker in the solid-phase synthesis of a urea library. Reac. Functional Polym. 52, 81-87(2002).

5. James. S.; Fritz; Orf, G. M. Extraction of metal ion with N, N-disubstituted amides. Anal. Chem. 47, 2043-2045(1975).

6. Al-Mulla E. A. J.; Yunus W. M. Z.; Ibrahim N. A. Abdul Rahman M. Z. Synthesis and characterization of N, N'carbonyl difatty amides from palm oil. J. Oleo Sci. 58, 467-471 (2009).

7. Hoidy, H. W.; Ahmad M. B.; Al-Mulla, E. A. J.; Yonus, W. M. Z.; Ibrahim, N. A. Synthesis and characterization of fatty hydroxamic acids from triacylclycerides. J. Oleo Sci. 59, 15-19 (2010).

8. Al-Mulla E. A. J .; Yunus W. M. Z.; Ibrahim N. A. Abdul Rahman M. Z. Enzymatic synthesis of fatty amides from palm olein J. Oleo Sci. 59, 59-64(2010).

9. Hoidy, H. W.; Ahmad M. B.; Al-Mulla, E. A. J.; Yonus, W. M. Z.; Ibrahim, N. A. Chemical synthesis of palm oilbased difatty acyl thiourea. J. Oleo Sci. 59, 229-233 (2010).

10. Al-Mulla E. A. J.; Yunus W. M. Z.; Ibrahim N. A. Abdul Rahman M. Z. Difatty acyl urea from corn oil: Synthesis and characterization. J. Oleo Sci. 59, 157-160 (2010).

11. Hoidy, H. W.; Ahmad M. B.; Al-Mulla, E. A. J.; Yonus, W. M. Z.; Ibrahim, N. A. Chemical synthesis and characterization of N-hydroxy-N-methyl fattyamide from 
palm oil. Oriental J. Chem. 26(2),(2010) in press.

12. Hoidy, H. W.; Ahmad M. B.; Al-Mulla, E. A. J.; Ibrahim, N. A. Modification of montmorillonite by difatty acyl thiourea using cation exchange process. Oriental J. Chem. 26 (2), (2010), in press.

13. Osman, A.; Nor A. Physical and chemical properties of shortenings from b palm oil: Tallow and palm olein: Tallow Blends with and without interesterification. $J$. Oil Palm Res. 11, 1-10 (1999).

14. Mohamad, S.; Yunus, W.; Haron, M.; Abdul Rahman, M. Z. Enzymatic synthesis of fatty hydrazides from palm oils. J. Oleo Sci. 57, 263-267(2008).

15. Romero, M. D.; Calvo, L.; Alba, C.; Daneshfar, A.; Ghaziaskar, H. S. Enzematic synthesis of isomyl acetate with immobilized Candida antarcteca lipase in n-hexane. Enzyme Microb. Technol. 37, 42-48 (2005).

16. Gandhi, N. N.; Sawant, S. B.; Joshi, J. B.; Studies on the lipozyme catalysed synthesis of butyl laurate. Biotechnol. Bioeng. 46, 1-12(1995).

17. Gunawan, E. R.; Basri, M.; Rahman, M. B.; Salleh, A. B.; Rahman, R. N. Lipase-catalyzed synthesis of palmbased wax ester. J. Oleo Sci. 53, 471-477(2004).

18. Hacking, M. A.; Akkus, H.; Ranteijk, V. F.; Sheldon, R. A. Lipase and esterase-catalyzed acylation of hetero-subsitituted nitrogen nucleophilic in waterand organic solvents. Biotechnol. Bioeng. 68, 84-91 (2000). 